\title{
EDITORIAL
}

\section{Predicting the cost of malaria elimination in the Asia-Pacific}

\section{[version 1; peer review: not peer reviewed]}

\author{
Rima Shretta ${ }^{1-3}$, Sheetal Silal (1D) 4-6, Lisa J. White (D) 6,7, Richard J. Maude (D)6-8
}

\author{
${ }^{1}$ Global Health Group, University of California, San Francisco, San Francisco, CA 94158, USA \\ ${ }^{2}$ Swiss Tropical and Public Health Institute, Basel 4002, Switzerland \\ 3University of Basel, Basel 4001, Switzerland \\ ${ }^{4}$ Modelling and Simulation Hub, Africa (MASHA), Department of Statistical Sciences, University of Cape Town, Rondebosch, Cape Town \\ 7700 , South Africa \\ ${ }^{5}$ South African DST-NRF Centre of Excellence in Epidemiological Modelling and Analysis, Stellenbosch University, Cape Town, South Africa \\ ${ }^{6}$ Centre for Tropical Medicine and Global Health, Nuffield Department of Medicine, University of Oxford, Oxford, Oxfordshire, UK \\ ${ }^{7}$ Mahidol-Oxford Tropical Medicine Research Unit, Faculty of Tropical Medicine, Mahidol University, Bangkok, Bangkok 10400, Thailand \\ ${ }^{8}$ Harvard TH Chan School of Public Health, Harvard University, Boston, MA, USA
}

\begin{abstract}
V1 First published: 24 Apr 2019, 4:73 (
https://doi.org/10.12688/wellcomeopenres.15166.1)

Latest published: 24 Apr 2019, 4:73(

https://doi.org/10.12688/wellcomeopenres.15166.1)

Abstract

Over the past decade, the countries of the Asia-Pacific region have made significant progress towards the goal of malaria elimination by the year 2030. It is widely accepted that for the region to meet this goal, an intensification of efforts supported by sustained funding is required. However, robust estimates are needed for the optimal coverage and components of malaria elimination packages and the resources required to implement them. In this collection, a multispecies mathematical and economic modelling approach supported by the estimated burden of disease is used to make preliminary estimates for the cost of elimination and develop an evidence-based investment case for the region.
\end{abstract}

Keywords

malaria, elimination, Asia-Pacific, economics, investment case

This article is included in the Mahidol Oxford

Tropical Medicine Research Unit (MORU)

gateway.

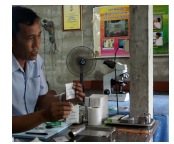

This article is included in the Predicting the cost of malaria elimination in the Asia-Pacific collection.

\section{Not Peer Reviewed \\ This article is an Editorial and has not been subject to external peer review.}

Any comments on the article can be found at the end of the article. 
Corresponding author: Richard J. Maude (Richard@tropmedres.ac)

Author roles: Shretta R: Conceptualization, Funding Acquisition, Project Administration, Supervision, Writing - Original Draft Preparation; Silal S: Writing - Review \& Editing; White LJ: Conceptualization, Project Administration, Supervision, Writing - Review \& Editing; Maude RJ:

Conceptualization, Funding Acquisition, Project Administration, Supervision, Writing - Review \& Editing

Competing interests: No competing interests were disclosed.

Grant information: This work was supported by the Wellcome Trust [106698]; the Asian Development Bank [TA-8763]; the Bill and Melinda Gates Foundation (BMGF) [OPP1089413]; and the Department of Foreign Affairs and Trade, Australian Government [71215].

The funders had no role in study design, data collection and analysis, decision to publish, or preparation of the manuscript.

Copyright: $\odot 2019$ Shretta R et al. This is an open access article distributed under the terms of the Creative Commons Attribution Licence, which permits unrestricted use, distribution, and reproduction in any medium, provided the original work is properly cited.

How to cite this article: Shretta R, Silal S, White LJ and Maude RJ. Predicting the cost of malaria elimination in the Asia-Pacific [version 1; peer review: not peer reviewed] Wellcome Open Research 2019, 4:73 (https://doi.org/10.12688/wellcomeopenres.15166.1)

First published: 24 Apr 2019, 4:73 (https://doi.org/10.12688/wellcomeopenres.15166.1) 


\section{Malaria elimination, transmission and costing in the Asia Pacific}

The Asia Pacific region has made unprecedented gains against malaria with cases and deaths declining by more than $50 \%$ since $2000^{1}$. Strong political commitment and financial support from governments and donors has enabled the scale-up of effective interventions against the disease, facilitating the decline. However, these gains are fragile, and investments could be lost if malaria resurges. Although domestic financing for malaria has increased in many countries in the last decade, countries continue to rely on external financing to deliver high impact interventions particularly to vulnerable populations. At the same time, given the low levels of mortality in Asia, there is a risk of withdrawal of funding as the disease may no longer be perceived as a priority and there is mounting competition for the limited government resources from other pressing disease concerns. The growing threat of antimalarial drug resistance arising from the Greater Mekong Subregion and the risk of it spreading to other regions makes the case for malaria elimination an urgent priority. However, in order to achieve a malaria-free Asia Pacific - a goal endorsed by leaders at the highest levels though the Asia Pacific Leaders Malaria Alliance (APLMA) - financial resources will need to be sustained. Countries and partners need better estimates of the resources required to eliminate malaria in the long term, as well as evidence on the economic benefits of investing in its elimination in order to advocate for more resources.

\section{How much financing do we actually need to eliminate malaria?}

There is limited understanding of the true volume of financing needed for malaria elimination due to a variety of reasons. Malaria programs in endemic countries are unable to capture the true burden of disease as data systems are often of poor quality and reporting is frequently incomplete. Furthermore, most information management systems do not capture the high volume of patients that access the often unregulated private sector and, in many countries, non-governmental organisations and therefore do not represent credible sources to estimate the financing needed for malaria services ${ }^{2}$. For example, the burden of malaria in India has been estimated to be anywhere between 8 and over 100 times the reported burden ${ }^{3}$, with the most recent estimate from the World Health Organization for 2017 being 8 to 15 times the reported burden, making a financial gap analysis challenging ${ }^{1,3}$.

Most country level estimates of need are obtained from National Strategic Plans (NSPs), which are often only available in countries eligible for financing from the Global Fund for HIV/TB and Malaria and are not always calibrated for elimination. Except for a few countries, these estimates of need do not incorporate interventions to improve efficiency or value for money; in many cases over-estimating the minimum costs required to deliver the plan. As NSPs are inadequate tools for cost estimation at the global level, models have been used to forecast need. While these have provided valuable projections of financing need in the absence of national level data, they have, to date, had limited applicability in Asia. Most of the models have been based on outputs of single species compartmental transmission models, almost exclusively focused on Plasmodium falciparum malaria transmission dynamics from sub-Saharan African countries. The ability of such a transmission model to simulate low or unstable levels of malaria transmission or the changing reservoir of parasites due to population movement and a diminishing population at risk is uncertain. They often assume universal coverage of all interventions and, as a result may overestimate costs. This may limit the models' usefulness for Asia, which has higher proportions of $P$. vivax, a lower overall burden, and the impact of malaria interventions such as Long-Lasting Insecticide Treated Nets and Indoor Residual Spraying differ from what has been observed for P. falciparum.

APLMA was established at the 2013 East Asia Summit (EAS) to accelerate progress towards a reduction in malaria cases and deaths in the region. In 2014, EAS Heads of Government agreed to the goal of an Asia-Pacific region free of malaria by 2030 and a "Leaders' Malaria Elimination Roadmap" was subsequently endorsed in $2015^{4}$.

As part of the evidence base for malaria elimination for the region, APLMA, with support from the Asian Development Bank, commissioned the Global Health Group at the University of California, San Francisco and Mahidol-Oxford Tropical Medicine Research Unit to estimate the burden of malaria in the Asia-Pacific region, predict the cost of elimination for a range of scenarios and develop an investment case for malaria elimination by 2030. This collection of papers presents the outputs from this work.

\section{Aims and scope}

The objectives of this body of work were to:

- Estimate the true burden of malaria in the Asia Pacific region. The annual clinical burdens of disease for both $P$. falciparum and $P$. vivax malaria were estimated for the 22 countries from 2000 to $2015^{5}$.

- Develop a mathematical model to project the most epidemiological efficient rates of decline to elimination by 2030. As the Asia-Pacific region experiences both $P$. falciparum and $P$. vivax malaria, the mathematical model incorporated the dynamics and control measures for both species ${ }^{6}$.

- Develop a software application that countries can use to visualize the effect of various scenarios of malaria control and elimination interventions to predict the optimal path to elimination in the region ${ }^{7}$.

- Estimate the cost to achieve malaria elimination in the Asia Pacific region by 2030 based on the above and to determine the economic impact of interventions against the transmission of $P$. falciparum and $P$. vivax malaria; 
generate an investment case for malaria by estimating the economic benefits of malaria elimination and prevention of reintroduction and; identify the funding gaps and explore the potential opportunities for generating financial resources for achieving malaria elimination goals ${ }^{8}$.

\section{Data availability}

No data is associated with this article.

\section{Grant information}

This work was supported by the Wellcome Trust [106698]; the Asian Development Bank [TA-8763]; the Bill and Melinda Gates Foundation (BMGF) [OPP1089413]; and the Department of Foreign Affairs and Trade, Australian Government [71215].

The funders had no role in study design, data collection and analysis, decision to publish, or preparation of the manuscript.
1. World Health Organization: World malaria report 2018. Geneva: World Health Organization; 2018 Reference Source

2. Mercado CE, Ekapirat N, Dondorp AM, et al: An assessment of national surveillance systems for malaria elimination in the Asia Pacific. Malar J. 2017; 16(1): 127. PubMed Abstract | Publisher Full Text | Free Full Text

3. Hay SI, Gething PW, Snow RW: India's invisible malaria burden. Lancet. 2010; 376(9754): 1716-7.

PubMed Abstract | Publisher Full Text | Free Full Text

4. APLMA: APLMA malaria elimination roadmap. Asia Pacific Leaders' Malaria Alliance; 2015.

Reference Source

5. Maude RJ, Mercado CEG, Rowley J, et al.: Estimating malaria disease burden in the Asia-Pacific [version 1; peer review: awaiting peer review]. Wellcome Open
Res. 2019; 4: 59

Publisher Full Text

6. Silal SP, Shretta R, Celhay OJ, et al.: Malaria elimination transmission and costing in the Asia-Pacific: a multi-species dynamic transmission mode [version 1; peer review: awaiting peer review]. Wellcome Open Res. 2019; 4: 62. Publisher Full Text

7. Celhay OJ, Silal SP, Maude RJ, et al.: An interactive application for malaria elimination transmission and costing in the Asia-Pacific [version 1; peer review: awaiting peer review]. Wellcome Open Res. 2019; 4:61. Publisher Full Text

8. Shretta R, Silal SP, Celhay OJ, et al: Malaria elimination transmission and costing in the Asia-Pacific: Developing an investment case [version 1; pee review: awaiting peer review]. Wellcome Open Res. 2019; 4: 60. Publisher Full Text 